\title{
A citizen science-based survey of avian mortality focusing on haemosporidian infections in wild passerine birds
}

\author{
Tanja Himmel, Josef Harl, Julia Matt and Herbert Weissenböck* (D)
}

\begin{abstract}
Background: Haemosporidioses are common in birds and their manifestations range from subclinical infections to severe disease, depending on the involved parasite and bird species. Clinical haemosporidioses are often observed in non-adapted zoo or aviary birds, whereas in wild birds, particularly passerines, haemosporidian infections frequently seem to be asymptomatic. However, a recent study from Austria showed pathogenic haemosporidian infections in common blackbirds due to high parasite burdens of Plasmodium matutinum LINN1, a common parasite in this bird species, suggesting that virulent infections also occur in natural hosts. Based on these findings, the present study aimed to explore whether and to what extent other native bird species are possibly affected by pathogenic haemosporidian lineages, contributing to avian morbidity.

Methods: Carcasses of passerine birds and woodpeckers were collected during a citizen science-based survey for avian mortality in Austria, from June to October 2020. Tissue samples were taken and examined for haemosporidian parasites of the genera Plasmodium, Haemoproteus and Leucocytozoon by nested PCR and sequencing the mitochondrial cytb barcode region, histology, and chromogenic in situ hybridization applying genus-specific probes.

Results: From over 160 dead bird reportings, 83 carcasses of 25 avian species were submitted for investigation. Overall haemosporidian infection rate was $31 \%$, with finches and tits prevailing species counts and infections. Sequence analyses revealed 17 different haplotypes (4 Plasmodium, 4 Haemoproteus, 9 Leucocytozoon), including 4 novel Leucocytozoon lineages. Most infected birds presented low parasite burdens in the peripheral blood and tissues, ruling out a significant contribution of haemosporidian infections to morbidity or death of the examined birds. However, two great tits showed signs of avian malaria, suggesting pathogenic effects of the detected species Plasmodium relictum SGS1 and Plasmodium elongatum GRW06. Further, exo-erythrocytic tissue stages of several haemosporidian lineages are reported.
\end{abstract}

Conclusions: While suggesting generally little contribution of haemosporidian infections to mortality of the investigated bird species, the findings indicate a possible role of certain haemosporidian lineages in overall clinical manifestation, either as main causes or as concurrent disease agents. Further, the study presents new data on exoerythrocytic stages of previously reported lineages and shows how citizen science can be used in the field of haemosporidian research.

Keywords: Citizen science, Dead bird, Plasmodium, Haemoproteus, Leuocytozoon, Exo-erythrocytic merogony, In situ hybridization, Avian malaria, Haemosporidioses

*Correspondence: herbert.weissenboeck@vetmeduni.ac.at Institute of Pathology, Department for Pathobiology, University

of Veterinary Medicine, Veterinärplatz 1, 1210 Vienna, Austria original author(s) and the source, provide a link to the Creative Commons licence, and indicate if changes were made. The images or other third party material in this article are included in the article's Creative Commons licence, unless indicated otherwise in a credit line to the material. If material is not included in the article's Creative Commons licence and your intended use is not permitted by statutory regulation or exceeds the permitted use, you will need to obtain permission directly from the copyright holder. To view a copy of this licence, visit http://creativecommons.org/licenses/by/4.0/. The Creative Commons Public Domain Dedication waiver (http://creativeco mmons.org/publicdomain/zero/1.0/) applies to the data made available in this article, unless otherwise stated in a credit line to the data. 


\section{Background}

Avian haemosporidians of the genera Plasmodium, Haemoproteus, and Leucocytozoon are arthropod-transmitted blood parasites with almost global distribution, infecting birds of diverse phylogenetic orders [1]. Counting more than 250 morphospecies [1,2] and over 4500 genetic lineages in the MalAvi database (http://130.235. 244.92/Malavi/ [3]), these protozoans vary considerably in their host specificity and pathogenicity $[4,5]$. While generally considered benign in most birds, avian haemosporidia can cause severe clinical diseases and mortality in susceptible hosts $[1,6]$. Birds without previous parasite exposure are particularly vulnerable and may experience severe parasitaemia during acute infections, resulting in haemolysis, anaemia, and death [7-9]. Birds may also die without premonitory signs, and fatalities are often linked to deleterious effects of exo-erythrocytic parasite stages in internal organs $[10,11]$.

Reports of clinical haemosporidioses frequently refer to domesticated or exotic bird species kept outside of their geographic origin such as in zoos or aviaries. In zoological settings, captive birds often live in close contact to the indigenous avifauna, which serves as a reservoir for haemosporidian parasites [9]. Transmission of the parasites to immunologically naïve bird hosts can result in increased virulence of otherwise non-pathogenic lineages, sometimes leading to disease outbreaks with high mortality rates, as, for example, regularly observed in Plasmodium-infected penguins [12] or Haemoproteusinfected parakeets [13]. In natural bird populations, haemosporidian disease outbreaks have been associated with the introduction of new lineages to naive host communities [14]. The probably best known example for the negative impact of haemosporidian infection on hosts without co-evolutionary adaption are Hawaiian honeycreepers, which have suffered severe population declines due to avian malaria after the introduction of both Plasmodium relictum GRW4 and its mosquito vector Culex quinquefasciatus to the islands around 1900 [14-16]. Similarly, in New Zealand, the introduction or translocation of avian hosts, together with the spread of invasive mosquito species, has led to multiple mortality events caused by avian malaria in several endemic bird species [17].

Apart from these well-documented cases of fatal haemosporidioses in naïve bird populations, little is known about Haemosporida-associated diseases and pathogenicity in wild birds inhabiting regions with local haemosporidian transmission. Field studies show that free-ranging birds often appear as asymptomatic carriers with low parasitaemia, suggesting subtle health effects of chronic infections in adapted hosts. Some studies revealed correlations of infections with increased physiological stress [18], reduced survival [19] and shorter lifespans [20], however, other studies yielded more ambiguous results [21, 22]. Besides consequences for host fitness, fatal haemosporidian infections have been described in a range of wild bird species, including gallinaceous birds [23], buzzards [24], falcons [25], different passerines [26-31], frogmouths [28], owls [32], woodpeckers [33], pigeons [34], and penguins [35, 36]. In addition to these mostly incidental reports in naturally infected birds, lethal haemosporidian infections were demonstrated in several experimentally infected passerines, providing indisputable evidence for the pathogenicity of certain lineages in wild birds [37].

It is important to note that in haemosporidian field studies, techniques for collecting free-ranging birds, such as the use of mist nets, may favour the capture of subclinically infected individuals, as sick birds might exhibit reduced mobility [38, 39]. In contrast, the detection of diseased or dead birds in the natural environment is problematic due to their rapid decomposition or removal by predators $[40,41]$, potentially resulting in biased sampling towards healthy birds. Considering these detection difficulties, it is conceivable that severe haemosporidioses, particularly acute infections, are underreported in wild birds.

Wildlife disease monitoring strategies such as routine pathological investigations of ad hoc submitted carcasses are fundamental to detecting wildlife morbidity and mortality, particularly when clinical manifestations are less obvious. While these investigations provide important epidemiological data by determining the presence or absence of particular pathogens, and identifying causes of death, they are constrained by the submission of carcasses. Citizen science, the participation of the public community in scientific research, offers a suitable approach to wildlife disease monitoring and has been used for the surveillance of different avian pathogens, including highly pathogenic avian influenza virus [42], West Nile virus [41, 43], Usutu virus [44], Salmonella typhimurium [45, 46], Mycoplasma gallisepticum [47], or Trichomonas gallinae [48]. By involving volunteer participants ("citizen scientists") in wildlife morbidity and mortality reporting, citizen science can facilitate the detection and recovery of carcasses of target species in both space and time, enabling large-scale epidemiological surveys and the collection of tissue samples [49].

Exploiting such archives of tissue samples, previous retrospective studies in Austria revealed an association of blackbird mortalities with the presence of widespread haemosporidian lineages $[30,50]$. Notably, severe parasite loads were linked to infections with Plasmodium matutinum LINN1, pointing towards its pathogenic role in these birds' mortalities. Single cases of virulent Plasmodium infections were also recorded in sparrows, tits, 
chaffinches, and woodpeckers [30], however, due to low sample sizes, it remains unclear to what extent these and other passerine species are affected by pathogenic lineages present in Austria. To address this question, the present study aimed to collect carcasses of passeriform and piciform birds by means of citizen science, and examine them for haemosporidian parasites.

\section{Methods}

\section{Study area and collection of bird carcasses}

For the collection of bird carcasses, a citizen science project was initiated in spring 2020. From June to October 2020, Austrian citizens were asked to report findings of dead birds and submit collected carcasses to the Institute of Pathology, University of Veterinary Medicine Vienna, for pathological examination. In order to reach a broad community of citizens, the survey was announced via different media prior to the start of the project, including a press release, local newspapers, radio interviews, and social media (Facebook). The survey was conducted in collaboration with the non-governmental organisation BirdLife Austria, and the urban wildlife project "StadtWildTiere". Reportings of dead birds were received via emails, telephone, and a reporting form made available on the website of "StadtWildtiere". In addition to the reports, citizen scientists sent photographs of the bird carcasses for species determination. A priori restrictions to the collection of dead birds included decomposed condition of the carcasses, and mortalities suspicious for finch trichomonosis. The dead birds were collected from all over Austria, however, for logistic reasons the geographic focus was on the Eastern federal states Vienna, Lower Austria and Burgenland. Citizen scientists were advised to store recovered bird carcasses in closed plastic bags at a cool place before their pick-up and transportation to the University of Veterinary Medicine Vienna by a medical courier service.

\section{Tissue sampling}

Necropsy was performed on submitted carcasses and tissue samples were collected from heart, lung, liver, spleen, kidney, brain, skeletal muscle, proventriculus, gizzard, intestine, bursa of Fabricius, and tibiotarsus for examination of the bone marrow. For molecular analyses, fresh samples of liver, lung, and brain were frozen and stored at $-20{ }^{\circ} \mathrm{C}$ until further processing. For histopathology and chromogenic in situ hybridization (CISH), tissue samples were fixed in $10 \%$ neutral buffered formalin for $24 \mathrm{~h}$ before routine embedding in paraffin wax. Formalin-fixed paraffin-embedded tissues (FFPE) were cut at 1-2 $\mu \mathrm{m}$ and stained with haematoxylin and eosin (HE). Morphological identification of haemosporidian tissue stages in HE-stained sections was based on parasite identification keys presented in the review by Valkiūnas and Iezhova [51].

\section{Molecular analyses}

Total DNA was extracted from frozen tissue samples using the DNeasy Blood \& Tissue Kit (Qiagen, Venlo, Netherlands) according to the manufacturer's instructions with one modification: the DNA was eluted twice with each $100 \mu \mathrm{l} \mathrm{AE} \mathrm{buffer,} \mathrm{and} \mathrm{the} \mathrm{second} \mathrm{eluate} \mathrm{was}$ used as template for the PCR. Molecular screening was done using a well-established nested PCR protocol targeting a partial sequence of the mitochondrial cytochrome b gene (cytb) of avian haemosporidians [52]. First, the outer primers HaemNFI and HaemNR3 were used to amplify DNA of Plasmodium, Haemoproteus, and Leucocytozoon. Second, the inner primer pairs HaemF/HaemR2 and HaemFL/HaemR2L were used to amplify DNA of Plasmodium/Haemoproteus, and Leucocytozoon, respectively. PCRs were performed in $25 \mu \mathrm{l}$ reaction volumes containing $14.375 \mu \mathrm{l}$ nuclease-free water, $5 \mu \mathrm{l} 5 \mathrm{X}$ Green GoTaq Flexi Buffer (Promega, Madison, Wisconsin, USA), $2 \mu \mathrm{l} \mathrm{MgCl}_{2}$ solution $(25 \mathrm{mM}$ ), $0.5 \mu \mathrm{l}$ PCR nucleotide mix (10 mM, Promega), $0.125 \mu \mathrm{l}$ GoTaq G2 Flexi DNA Polymerase (5 u/ $\mu \mathrm{l}$, Promega), each $1 \mu \mathrm{l}$ forward and reverse primers $(10 \mathrm{pmol} / \mu \mathrm{l})$, and $1 \mu \mathrm{l}$ DNA template or, in case of the second PCRs, $1 \mu \mathrm{l}$ amplicon from the first PCR. All reactions were run initial $2 \mathrm{~min}$ at $94{ }^{\circ} \mathrm{C}$, followed by 35 cycles of $30 \mathrm{~s}$ denaturation at $94{ }^{\circ} \mathrm{C}, 30 \mathrm{~s}$ primer annealing at $50{ }^{\circ} \mathrm{C}$, and $1 \mathrm{~min}$ extension at $72{ }^{\circ} \mathrm{C}$, followed by $10 \mathrm{~min}$ final extension at $72{ }^{\circ} \mathrm{C}$. PCR success was checked by gel electrophoresis of the PCR products on $1 \%$ agarose gels with Midori Green Advance (Nippon Genetics Europe, Dueren, Germany) and visualization of amplicons using a BioSens SC-Series 710 gel documentation system (GenXpress, Wiener Neudorf, Austria). Tissue samples were processed along with positive controls (samples confirmed positive in previous screenings) and negative controls (nuclease-free water) in every PCR run. PCR amplicons from the second PCRs were sent to Microsynth Austria for bi-directional sequencing. Obtained sequences and electropherograms were analyzed with Bioedit [53]. Sequences with ambiguous characters, indicating multiple infections, were double checked and un-phased using DnaSP v.6.12.3 [54]. All sequences were subjected to BLAST search in the avian malaria database MalAvi (http://130.235.244.92/Malavi/ [3]) and NCBI GenBank. Haplotypes not matching 100\% with previously published $c y t b$ lineages were assigned new lineage names according to MalAvi rules [3]. Nucleotide sequences of the detected haemosporidians were uploaded to GenBank under the accession numbers MZ465327- MZ465365. 
In addition to Haemosporida-PCR screening, tissue samples of birds that showed macroscopic lesions suggestive for Trichomonas infection during necropsy were screened for the presence of Trichomonas parasites. For this purpose, esophagus and crop samples were subjected to DNA-extraction and PCR using previously established primers (forward primer $5^{\prime}$-GGT AGG CTA TCA CGG GTA AC-3', reverse primer 5'-ACT YGC AGA GCT GGA ATT AC-3'), which target a 247-249 bp section of the $18 \mathrm{~S}$ ribosomal RNA gene of parasites belonging to the order Trichomonadida [55].

\section{Chromogenic in situ hybridization}

To detect haemosporidian parasites in tissue sections, FFPE tissue blocks of PCR-positive birds were cut into 1-2 $\mu \mathrm{m}$ thick sections, one of which was stained with HE and the remaining were subjected to CISH. Chromogenic in situ hybridization was performed following previously established protocols using genus-specific oligonucleotide probes for the detection of Haemoproteus and Leucocytozoon [56]. For the detection of Plasmodium, an oligonucleotide probe was designed based on $18 S$ ribosomal RNA gene sequences of Plasmodium spp. [57]. In addition, species-specific probes were designed for the detection of Plasmodium relictum and Plasmodium elongatum. These probes were previously tested on tissues featuring single infections with the respective parasites, ruling out cross-reactions. For all cases with mixed infections, as determined by PCR and sequencing, several sections were separately incubated with the relevant probes. Sequences of all probes used in this study are provided in Table 1.

$\mathrm{CISH}$ procedure was done as previously described in $[30,56]$. In brief, tissue sections were deparaffinized, rehydrated in a series of graded ethanol (100\%, 96\%, $70 \%)$ and subjected to proteolytic treatment with proteinase $\mathrm{K}$ (Roche, Basel, Switzerland) for $40 \mathrm{~min}$ at $37^{\circ} \mathrm{C}$. Thereafter, sections were rinsed in distilled water, dehydrated in 96\% and 100\% ethanol and air-dried before incubation with hybridization solution containing 1 or $10 \mathrm{ng}$ digoxigenin-labelled probe per $100 \mu \mathrm{l}$. Hybridization was done overnight in a humid chamber at $40{ }^{\circ} \mathrm{C}$. On the following day, after stringency washes in $2 \mathrm{X}, 1 \mathrm{X}$,
0.1X SSC buffer 10 min each, tissue sections were covered with blocking solution containing normal goat serum and $10 \%$ Triton X-100 for 30 min before application of anti-digoxigenin-AP Fab-fragments (Roche) at a concentration of 1:200 for $1 \mathrm{~h}$ at room temperature. After two washes in distilled water for $15 \mathrm{~min}$, tissue sections were incubated with NBT/BCIP (nitro-blue tetrazolium chloride/5-bromo-4-chloro-3'-indolyphosphate p-toluidine salt, Roche) mixed with levamisole in $0.1 \mathrm{M}$ Trisbuffered saline ( $\mathrm{pH}$ 9.5) for minimum 40 min in a dark, humid chamber. After stopping the chromogenic reaction with Tris-EDTA buffer ( $\mathrm{pH} 8.0$ ) for $10 \mathrm{~min}$, sections were counterstained with haematoxylin and mounted using Aquatex (Merck Millipore) and coverslips. All in situ hybridized sections were evaluated using brightfield microscopy and 100-400× magnifications. Based on the location, size, and shape of the chromogenic signal, a distinction was made between signals representing blood stages of the parasite and signals representing exoerythrocytic tissue stages. For example, signals found in the lumen of blood vessels measuring up to the size of erythrocytes were regarded as blood stages, whereas signals located in other host cells and exceeding the size of erythrocytes were regarded as exoerythrocytic meronts. Detailed descriptions and examples on how CISH signals were distinguished can be found in [50]. In addition, corresponding HE-stained sections were checked to confirm presence or absence of exoerythrocytic stages. To be able to compare infection intensities, the abundance of blood stage signals was scored for each case as low (0-3 signals in a blood vessel of approximately $100 \mu \mathrm{m}$ in diameter), moderate (4-20 signals) or high (more than 20 signals).

\section{Results \\ Dead bird reports}

From June to October 2020 at least 166 reports counting more than 326 dead birds of 31 species and 17 families were received via website or email. As intended, the majority of reported dead birds were members of the order Passeriformes (296 individuals) and Piciformes (23). Seven dead birds belonged to the orders Columbiformes (3), Coraciiformes (1), Falconiformes (1), Pelecaniformes (1) and Galliformes (1). Among passeriform

Table 1 Oligonucleotide probes used for the detection of avian haemosporidian parasites by chromogenic in situ hybridization

\begin{tabular}{llll}
\hline Probe & Sequence & Work concentration & Target \\
\hline Plasmo18S_1 & 5'-CTTAAACTTCCTTGTGTTAGACACACAAT-3' & $1 \mathrm{ng} / 100 \mu \mathrm{l}$ & Plasmodium spp. \\
Haemo18S_1 & 5'-GCTAACCGTAGTTATAGTCGCCATCTC-3' & $1 \mathrm{ng} / 100 \mu \mathrm{l}$ & Haemoproteus (Parahaemoproteus) spp. $\quad$ Himmel et al. [56] \\
Leuco18S_1 & 5'-TAGGACTCCCCACTTGTCTTTTTCTTGA-3' & $1 \mathrm{ng} / 100 \mu \mathrm{l}$ & Leucocytozoon spp. \\
Prel18S & 5'-ACCATTTAACACGTATCCGATAAAGCATTACC-3' & $10 \mathrm{ng} / 100 \mu \mathrm{l}$ & Plasmodium relictum (SGS1) \\
Pelo18S & 5'-CAACTGTTACATTGGGACGCCTTT-3' & $10 \mathrm{ng} / 100 \mu \mathrm{l}$ & Plasmodium elongatum (GRW06) \\
\hline
\end{tabular}


birds, finches (Fringillidae) were most frequently reported, particularly European greenfinches Chloris chloris with over 85 individuals, followed by common chaffinches Fringilla coelebs (29) and European goldfinches Carduelis carduelis (21). Other reported passeriform birds included species of Turdidae (30), Paridae (20), Passeridae (18), Hirundinidae (14), Muscicapidae (10), Sylviidae (3), Sturnidae (2), Corvidae (2), Regulidae (1) and Emberizidae (1). Among Piciformes, the great spotted woodpecker Dendrocopos major was most frequently reported with ten individuals, followed by the European green woodpecker Picus viridis with six individuals.

The majority of dead birds (over 75\%) were registered between June and August 2020. As the geographic focus of the survey was on eastern Austria, about half of the reported birds were found in the federal state Lower Austria (154), followed by the capital Vienna (41) and Burgenland (30), however, reports were also received from more western federal states. Most birds were found on private property, either in the garden or around the house, for example on the balcony or terrace. A high percentage of the citizen scientists stated to feed birds regularly.

\section{Pathological examinations}

In total, 83 individuals were collected by the citizen scientists and submitted for pathological examination. Due to high numbers of birds not suitable for investigation, the number of submitted carcasses was lower compared to reported dead bird counts. Two of the 83 submitted birds were not examined due to their advanced decomposition at the time of delivery. Except for these two individuals, which could only be identified to genus level, all birds were identified to species level. Among the submitted birds, great tits Parus major and common chaffinches Fringilla coelebs were the most common species with 10 and 9 individuals, respectively (Table 2). In 24 of 81 birds, gross examination showed signs of trauma from bird strikes (i.e. collision with structures such as windows), for example subdermal intracranial haemorrhages, crushes, or blood in the thoraco-abdominal cavity. In finches, gross lesions suggestive of avian trichomonosis such as yellowish and necrotic masses on the oral mucosa, oesophagus, or crop were frequently observed (see Additional file 1). Other abnormalities observed during necropsy included spleno- and hepatomegaly, and dark or bloody contents in the intestines.

\section{Haemosporidian prevalence and diversity}

By PCR, 25 (31\%) of 81 submitted birds tested positive for haemosporidian parasites of the genera Plasmodium, Haemoproteus or Leucocytozoon, however the proportion of infected birds varied strongly between host species (Table 2). A $100 \%$ infection rate was found in common chaffinches Fringilla coelebs $(\mathrm{n}=9)$, hawfinches Coccothraustes coccothraustes $(\mathrm{n}=3)$, blue tits Cyanistes caeruleus $(\mathrm{n}=3)$, blackbirds Turdus merula $(\mathrm{n}=2)$, the bullfinch Pyrrhula pyrrhula $(\mathrm{n}=1)$ and Eurasian bittern Botaurus stellaris $(\mathrm{n}=1)$. Among great tits Parus major $(\mathrm{n}=10) 40 \%$ of the birds were haemosporidian-positive, whereas European goldfinches Carduelis carduelis $(\mathrm{n}=6)$ and European green finches Chloris chloris $(\mathrm{n}=7)$ were less often infected with $17 \%$ and $14 \%$, respectively. Among all examined birds, the three genera Plasmodium, Haemoproteus and Leucocytozoon were similarly prevalent with 9, 10, and 10 infected birds, respectively. Eight (32\%) of the 25 positive birds showed mixed infection with parasites of the same genus (2) or different genera (5). By sequencing, 17 unique $c y t b$ lineages were identified, most of which were identical to haplotypes previously deposited in the MalAvi database or Genbank (Table 2). The majority of lineages were recorded in finches and tits, which accounted for half of all examined birds. For two known cytb lineages, new host-parasite associations were identified, including SYAT05, a lineage of Plasmodium vaughani, detected in a goldfinch Carduelis carduelis, and BT2 (Leucocytozoon sp.), detected in a bullfinch Pyrrhula pyrrhula. Four Leucocytozoon lineages (COCCO01, COCCOC02, CYACAE07, BOTSTEL01) were recorded for the first time in this study. Figure 1 shows the geographic distribution of all investigated birds and detected haemosporidian lineages. Detailed information for individual positive cases are provided in Additional file 1.

\section{Chromogenic in situ hybridization}

Concordant with the PCR results, CISH showed parasite stages in the histological samples of all 25 infected birds (Table 3). In most cases, detected CISH signals were confined to the lumen of blood vessels. As the intraluminal signals were relatively small (not larger than 5-6 $\mu \mathrm{m}$ ) and endothelial meronts could not be observed in corresponding HE-stained sections, these stages were classified as blood stages of the parasites. In contrast to blood stages, parasite tissue stages were only observed in five birds (Table 3; Fig. 2).

Two of three hawfinches exhibited Leucocytozoon tissue stages in their kidneys (Fig. 2a-i). Overall, the abundance of tissue stages was low in both birds. The meronts were mostly located in renal tubules and varied in size and maturity of the developmental stages. In some of the infected host cells an enlarged cell nucleus, characteristic for Leucocytozoon, was visible (Fig. 2f, g). In other organs, meronts were not observed. Leucocytozoon parasite stages were also found in the Eurasian bittern infected 
Table 2 Haemosporidian parasites detected in dead birds submitted between June and October 2020 and screened by PCR

\begin{tabular}{|c|c|c|c|c|c|c|c|c|}
\hline \multirow[t]{2}{*}{ Bird family } & \multirow[t]{2}{*}{ Host species } & \multirow[t]{2}{*}{$n$} & \multirow{2}{*}{$\begin{array}{l}\text { Sample origin } \\
\text { (Federal state) }\end{array}$} & \multicolumn{4}{|c|}{ PCR positive } & \multirow[t]{2}{*}{ Parasite species \& cytb lineages ${ }^{a}$} \\
\hline & & & & Plas & Haem & Leuc & Total (\%) & \\
\hline \multirow[t]{3}{*}{ Passeridae } & Passer domesticus & 2 & $V(1), L A(1)$ & - & - & - & $0(0 \%)$ & \\
\hline & Passer montanus & 1 & LA & - & - & - & $0(0 \%)$ & \\
\hline & Passer sp. & 2 & LA & - & - & - & $0(0 \%)$ & \\
\hline \multirow[t]{7}{*}{ Fringillidae } & Carduelis carduelis & 6 & $\operatorname{LA}(2), S(1), T(3)$ & 1 & - & - & $1(17 \%)$ & P. vaughani SYAT05 \\
\hline & Chloris chloris & 7 & $V(2), L A(1), S(1), B(3)$ & - & 1 & - & $1(14 \%)$ & Haemoproteus sp. CARCHL01 \\
\hline & Fringilla coelebs & 9 & $V(1), L A(6), S(1), B(1)$ & 1 & 7 & 2 & $9(100 \%)$ & $\begin{array}{l}\text { P. relictum GRW11 (1), } \\
\text { Haemoproteus sp. CCF23 (7), Leucocytozoon } \\
\text { sp. BRAM3 (2) }\end{array}$ \\
\hline & Coccothraustes coccothraustes & 3 & LA (3) & - & 1 & 3 & $3(100 \%)$ & $\begin{array}{l}\text { Haemoproteus sp. HAWF6 (1), Leucocy- } \\
\text { tozoon sp. HAWF7 (3), Leucocytozoon sp. } \\
\text { COCCOC01 (2), Leucocytozoon sp. COC- } \\
\text { COC02 (1) }\end{array}$ \\
\hline & Pyrrhula pyrrhula & 1 & $\mathrm{~T}$ & - & 1 & 1 & $1(100 \%)$ & $\begin{array}{l}\text { Haemoproteus cf. majoris EMSPO03, } \\
\text { Leucocytozoon sp. PARUS25, Leucocytozoon } \\
\text { sp. BT2 }\end{array}$ \\
\hline & Serinus serinus & 1 & $\mathrm{~T}$ & - & - & - & $0(0 \%)$ & \\
\hline & Linaria cannabina & 1 & LA & - & - & - & $0(0 \%)$ & \\
\hline \multirow[t]{2}{*}{ Paridae } & Parus major & 10 & $V(4), \operatorname{LA}(5), B(1)$ & 4 & - & 1 & $4(40 \%)$ & $\begin{array}{l}\text { P. elongatum GRW06 (4), } \\
\text { P. relictum SGS1 (2), } \\
\text { Leucocytozoon sp. PARUS4 (1) }\end{array}$ \\
\hline & Cyanistes caeruleus & 3 & $\mathrm{~V}(2), \cup A(1)$ & 1 & - & 2 & $3(100 \%)$ & $\begin{array}{l}\text { P. elongatum GRW06 (1), Leucocytozoon sp. } \\
\text { PARUS4 (2), Leucocytozoon sp. CYACAE07 } \\
\text { (1) }\end{array}$ \\
\hline Hirundinidae & Hirundo rustica & 5 & LA (5) & - & - & - & $0(0 \%)$ & \\
\hline Sylviidae & Sylvia atricapilla & 2 & $\mathrm{LA}(1), \mathrm{B}(1)$ & - & - & - & $0(0 \%)$ & \\
\hline Regulidae & Regulus regulus & 1 & V & - & - & - & $0(0 \%)$ & \\
\hline \multirow[t]{2}{*}{ Muscicapidae } & Phoenicurus ochruros & 3 & $V(3)$, LA (1) & - & - & - & $0(0 \%)$ & \\
\hline & Erithacus rubecula & 3 & LA (3) & - & - & - & $0(0 \%)$ & \\
\hline \multirow[t]{2}{*}{ Turdidae } & Turdus philomelos & 1 & LA & - & - & - & $0(0 \%)$ & \\
\hline & Turdus merula & 2 & LA (1), UA (1) & 2 & - & - & $2(100 \%)$ & P. vaughani SYAT05 (2) \\
\hline Sturnidae & Sturnus vulgaris & 3 & $V(3)$ & - & - & - & $0(0 \%)$ & \\
\hline \multirow[t]{3}{*}{ Picidae } & Picus viridis & 6 & $\mathrm{LA}(5), \mathrm{B}(1)$ & - & - & - & $0(0 \%)$ & \\
\hline & Dendrocopos major & 5 & $L A(3), B(2)$ & - & - & - & $0(0 \%)$ & \\
\hline & Leiopicus medius & 2 & $V(1), L A(1)$ & - & - & - & $0(0 \%)$ & \\
\hline Alcedinidae & Alcedo atthis & 1 & B & - & - & - & $0(0 \%)$ & \\
\hline Ardeidae & Botaurus stellaris & 1 & V & - & - & 1 & $1(100 \%)$ & Leucocytozoon sp. BOTSTEL01 \\
\hline Total & & 81 & & 9 & 10 & 10 & 25 & 17 lineages (4 Plas, 4 Haem, 9 Leuc) \\
\hline
\end{tabular}

V: Vorarlberg; LA: Lower Austria; S: Salzburg; T:Tyrol; B: Burgenland; V = Vienna Plas: Plasmodium; Haem: Haemoproteus; Leuc: Leucocytozoon

${ }^{a}$ Numbers in parentheses indicate total infected birds. Lineages in bold represent novel cytb haplotypes

with Leucocytozoon sp. BOTSTEL01. However, compared to plenty blood stages observed in diverse organs, only few meronts were found in the muscle layer of the gizzard and in the in the mucosa of proventriculus and intestine (Fig. 2j-1).

Two finches exhibited tissue stages of Haemoproteus spp. in their organs. In one of them, a common chaffinch infected with Haemoproteus sp. CCF23, few small meronts were found in the liver as well as a single megalomeront in the pectoral muscle (Fig. $2 \mathrm{~m}$ ). In the other bird, a bullfinch infected with Haemoproteus cf. majoris EMSPO03, a single megalomeront of approximately $200 \mu \mathrm{m}$ was detected in the muscle wall of the gizzard (Fig. 2n). Examination of additional tissue sections did not reveal any further megalomeronts in these birds.

Among the Plasmodium-infected birds, tissue stages were scarce or absent. One of the great tits infected with Plasmodium elongatum GRW06, showed severe 


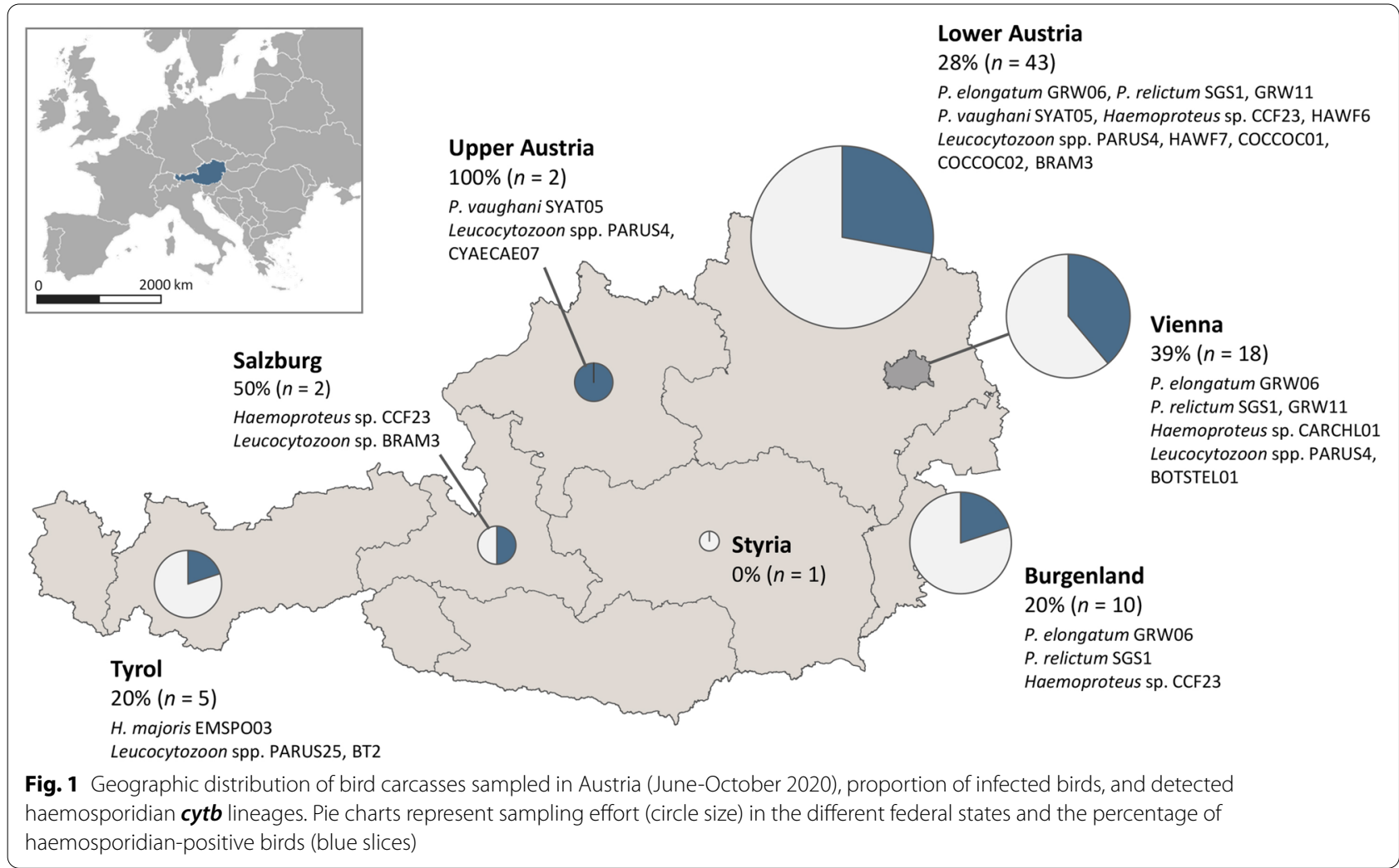

macroscopic enlargement of spleen, indicating pathological involvement. CISH revealed plenty Plasmodium stages in the spleen, however, due to autolysis, tissue stages could not be identified in corresponding HEstained sections. In another great tit, co-infected with P. elongatum GRW06 and P. relictum SGS1, numerous blood stages were observed in the vasculature, indicating heavy parasitaemia (Fig. 2o). To resolve the identity of the detected parasite stages in this case, CISH was repeated using species-specific probes for $P$. elongatum and $P$. relictum, revealing positive signals with both probes (Additional file 2). In none of the P. elongatum-infected birds, parasite stages were found in haematopoietic stem cells in the bone marrow.

Apart from splenic enlargement in the $P$. elongatum GRW06-infected tit, no pathologic changes were observed in association with the detected tissue stages.

\section{Discussion}

This study reports on haemosporidian infections in wild passerine birds from Austria collected via dead bird monitoring using a citizen science approach. This method of sampling was used for the first time in avian haemosporidian research. Based on previously reported virulent Plasmodium infections in Common blackbirds [50], the present study aimed to explore whether and to what extent other native bird species are affected by severe parasite burdens of pathogenic haemosporidian lineages, contributing to avian mortality.

The study showed that citizen science can be beneficial for obtaining carcasses of naturally infected birds within a reasonable time period. In contrast to exploring haemosporidian infections in living birds, the investigation of bird carcasses offers the possibility to address questions related to the exo-erythrocytic development of the parasites, which remains underinvestigated in wild birds. Particularly for Haemoproteus and Leucocytozoon species, current knowledge about their exoerythrocytic life cycle remains fragmentary and requires additional research [51]. The examination of organ samples of infected birds not only allows the detection and morphological description of developing tissue stages but also histologic assessment of affected organs. This is particularly important for determining infection severity and pathogenicity of haemosporidian species or lineages in different host species and better understanding the pathogenesis of Haemosporida-associated diseases. While citizen science provides an ideal framework to collect samples for such investigations, the sampling outcome in this study was constrained by several factors related to organization of the survey. First, participation of citizen scientists greatly depended on the publicity of 
Table 3 Haemosporidian parasites detected by CISH in bird carcasses collected in Austria from June to October 2020

\begin{tabular}{|c|c|c|c|c|}
\hline Case ID & Host species & Parasite species \& cyt $B$ lineages & $\begin{array}{l}\text { Abundance of } \\
\text { blood stages }^{a}\end{array}$ & $\begin{array}{l}\text { Distribution of } \\
\text { tissue stages }^{\mathrm{a}}\end{array}$ \\
\hline $\mathrm{AH} 2017$ & Carduelis carduelis & P.vaughani SYAT05 & + & - \\
\hline $\mathrm{AH} 2138$ & Chloris chloris & Haemoproteus sp. CARCHL01 & + & - \\
\hline $\mathrm{AH} 2019$ & Fringilla coelebs & Haemoproteus sp. CCF23 & ++ & - \\
\hline $\mathrm{AH} 2035$ & Fringilla coelebs & Haemoproteus sp. CCF23 & + & - \\
\hline $\mathrm{AH} 2036$ & Fringilla coelebs & Haemoproteus sp. CCF23 & + & - \\
\hline $\mathrm{AH} 2037$ & Fringilla coelebs & Haemoproteus sp. CCF23 & ++ & $\begin{array}{l}\text { Liver (meront) \& pectoral muscle (mega- } \\
\text { lomeront) }\end{array}$ \\
\hline $\mathrm{AH} 2038$ & Fringilla coelebs & Leucocytozoon sp. BRAM3 & + & - \\
\hline AH2049 & Fringilla coelebs & $\begin{array}{l}\text { Haemoproteus sp. CCF23, Leucocytozoon sp. } \\
\text { BRAM3 }\end{array}$ & $+(H, L)$ & - \\
\hline $\mathrm{AH} 2050$ & Fringilla coelebs & Haemoproteus sp. CCF23 & + & - \\
\hline $\mathrm{AH} 2137$ & Fringilla coelebs & Haemoproteus sp. CCF23 & + & - \\
\hline $\mathrm{AH} 2141$ & Fringilla coelebs & P. relictum GRW11 & + & - \\
\hline $\mathrm{AH} 2024$ & Coccothraustes coccothraustes & $\begin{array}{l}\text { Haemoproteus sp. HAWF6, Leucocytozoon sp. } \\
\text { HAWF7, Leucocytozoon sp.COCCOC01 }\end{array}$ & $+(H, L)$ & Kidney (meronts) (L) \\
\hline $\mathrm{AH} 2025$ & Coccothraustes coccothraustes & $\begin{array}{l}\text { Leucocytozoon sp. HAWF7, Leucocytozoon } \\
\text { sp. COCCOC01, Leucocytozoon sp. COC- } \\
\text { COC02 }\end{array}$ & ++ & - \\
\hline $\mathrm{AH} 2034$ & Coccothraustes coccothraustes & Leucocytozoon sp. HAWF7 & ++ & Kidney (meronts) \\
\hline $\mathrm{AH} 2023$ & Pyrrhula pyrrhula & $\begin{array}{l}\text { Haemoproteus cf. majoris EMSPO03, Leucocy- } \\
\text { tozoon sp. PARUS25, Leucocytozoon sp. BT2 }\end{array}$ & $++(H)_{1}+(L)$ & Gizzard (megalomeront) $(H)$ \\
\hline $\mathrm{AH} 2018$ & Cyanistes caeruleus & $\begin{array}{l}\text { Leucocyotzoon sp. PARUS4, Leucocytozoon sp. } \\
\text { CYACAE07 }\end{array}$ & + & - \\
\hline $\mathrm{AH} 2033$ & Cyanistes caeruleus & Leucocytozoon sp. PARUS4 & + & - \\
\hline $\mathrm{AH} 2043$ & Cyanistes caeruleus & P. elongatum GRW06 & + & - \\
\hline $\mathrm{AH} 2011$ & Parus major & $\begin{array}{l}\text { P. elongatum GRW06, Leucocytozoon sp. } \\
\text { PARUS4 }\end{array}$ & $+(P, L)$ & - \\
\hline $\mathrm{AH} 2022$ & Parus major & P. elongatum GRW06 & + & - \\
\hline $\mathrm{AH} 2032$ & Parus major & P. relictum SGS1, P. elongatum GRW06 & + & - \\
\hline AH2039 & Parus major & P. relictum SGS1, P. elongatum GRW06 & +++ & - \\
\hline $\mathrm{AH} 2140$ & Turdus merula & P. vaughani SYAT05 & + & - \\
\hline $\mathrm{AH} 2149$ & Turdus merula & P. vaughani SYAT05 & + & - \\
\hline $\mathrm{AH} 2147$ & Botaurus stellaris & Leucocytozoon sp. BOTSTEL01 & + & Proventriculus, gizzard \& intestine (meronts) \\
\hline
\end{tabular}

the survey. For example, the response quote of citizen scientists was great after the first announcement at the beginning of the survey, but decreased over the following weeks, demanding further advertisement to raise public awareness and motivate citizens to report bird mortalities. Second, not all reported bird carcasses were suitable for collection due to their advanced decomposition or the lack of possibilities by the citizen scientists to store the collected birds adequately. Although haemosporidian parasites can be detected by CISH even in less-well preserved tissues samples, advanced autolysis prevents their morphological assessment in histological sections. Third, for logistic reasons, dead bird collection was geographically restricted, limiting overall bird sample size. Thus, to maximize sampling outcome, good publicity and communication with the citizen scientists before and during the survey, as well as logistical aspects concerning adequate storage, handling and transportation of collected carcasses need to be considered in future studies applying citizen science for the purpose of bird carcass collection.

Another important aspect to consider when collecting dead birds for investigating haemosporidian infections is sampling bias towards certain bird hosts. This is particularly critical with respect to comparing infection rates or apparent prevalences of haemosporidian parasites in bird 

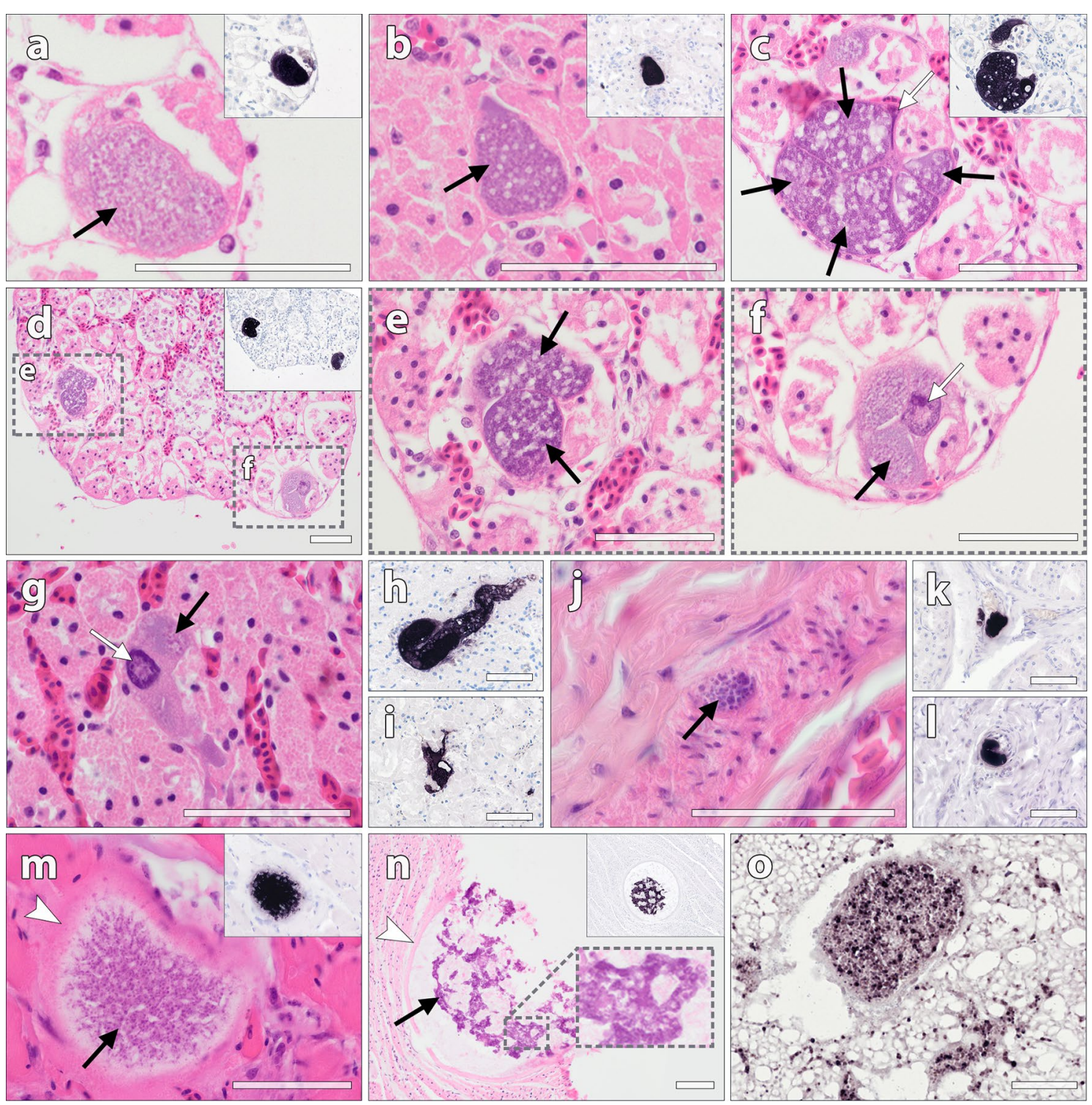

Fig. 2 Parasite tissue stages of Leucocytozoon, Haemoproteus and Plasmodium in naturally infected wild birds, identified by CISH and in HE-stained sections. a-f Multiple meronts of Leucocytozoon sp. in the kidneys of a hawfinch coinfected with Haemoproteus and Leucytozoon. CISH using a Leucocytozoon-specific probe showed strong labelling of meronts in infected kidney cells, confirming their generic identity (inserts a-d). The meronts (black arrows) were mostly located in renal tubular cells and contained developing merozoites of varying maturity. Occasionally, a deformed or enlarged host cell nucleus, characteristic for Leucocytozoon-infected host cells, was visible (c, $\mathbf{f}$, white arrows). $\mathbf{g}$-i Leucocytozoon tissue stages in the kidneys of a hawfinch infected with the lineage HAWF7. The parasite stages were located in single infected host cells (g, black arrow), sometimes featuring an enlarged host cell nucleus (white arrow), or in multiple adjacent host cells (presumably renal tubule cells) (h), or in the intertubular space (i). $\mathbf{j}-\mathbf{I}$ Leucocytozoon meronts in the proventriculus of an Eurasian bittern infected with Leucocytozoon sp. BOTSTEL01. m A Haemoproteus megalomeront in the pectoral muscle of a common chaffinch infected with Haemoproteus sp. CCF23, labelled by the Haemoproteus-specific probe (insert). The megalomeront contained numerous developing merozoites (black arrow), enclosed by an indistinct eosinophilic wall (white arrowhead). $\mathbf{n}$ A megalomeront detected in the muscular layer of the gizzard in a bullfinch infected with Haemoproteus sp. EMSPO03. The megalomeront was bounded by a thick eosinophilic wall (white arrowhead) and contained irregularly shaped, strongly basophilic cytomeres with developing merozoites (black arrow). o Plasmodium blood stages detected by CISH in the lung of a great tit co-infected with $P$. relictum SGS1 and P. elongatum GRW06. Scale bars: $50 \mu \mathrm{m}$ 
carcasses to studies investigating living birds, and drawing conclusions about their pathogenicity. In the present study, dead bird sampling was strongly biased towards fringillid species. While species abundance certainly played a role here, this sampling bias can be explained by high mortality rates due to finch trichomonosis, an emerging infectious disease with high seasonality in mid-late summer. This protozoal disease primarily affects green finches, but also other finch species, albeit much less frequently [58], and has spread through Europe within the last decade, including Austria [59]. For this reason, the collection of green finch carcasses was restricted to fatalities not indicative for trichomonosis based on the citizen scientists' reports (e.g. reported lethargy, ruffled plumage in combination with dysphagia). Yet, the pathological examinations revealed, that most of the collected finches had macroscopic lesions consistent with $T$. gallinae infection, indicating that these birds probably suffered from trichomonosis.

Keeping in mind its limitations and potential biases regarding bird collection, citizen science could present a complementary tool to study haemosporidian parasites in birds. Apart from generating scientific data, the involvement of citizen scientists in bird carcass collection also increases public awareness about avian diseases and bird health, which can be beneficial for engagement in bird conservation projects and general greater interest in science.

Including 81 birds of 24 passerine and non-passerine species, this investigation showed haemosporidian parasites in $31 \%$ of the birds, however, the proportion of infected birds varied considerably across host species. With finches and tits dominating in numbers, the majority of the infected birds presented low parasite burdens in both blood and tissues. Particularly tissue stages of Haemoproteus and Leucocytozoon parasites have been reported to cause haemorrhages and necroses or provoke inflammatory processes $[7,13,50,60]$, however, in none of the cases investigated here, tissue reactions were associated with the detected meronts or megalomeronts, suggesting an overall minor role of these parasites for the bird fatalities. Instead, most bird deaths probably resulted from other causes, most of all traumatic injuries and fatal infections with Trichomonas parasites (Additional file 1). However, two great tits clearly showed signs of avian malaria, indicating detrimental effects of the involved Plasmodium parasites. One of the two birds exhibited marked parasitaemia as demonstrated by abundant CISH signals in the blood, whereas the other had numerous parasite stages in the spleen, associated with severe splenic enlargement. Although it remains questionable whether avian malaria was more than a contributory factor for death of the birds, these two cases are particularly interesting, as both featured infections with $P$. elongatum GRW06, a generalist parasite rarely documented in species of the Paridae so far. This parasite infects numerous avian species of different families worldwide (MalAvi database, [2]) and can be highly virulent for non-adapted hosts [61-63]. However, with only two reports of GRW06 in a great tit [57] and blue tit [64] from Austria, records from the family Paridae are virtually absent. Notably, in the present study, GRW06 was found in four of ten great tits and one of three blue tits. The positive CISH results with the $P$. elongatum-specific probe detecting parasite stages in the tissues suggest that this parasite is able to develop in Paridae species. However, assuming that tits are susceptible to P. elongatum GRW06, it remains difficult to explain why P. elongatum GRW06 has been absent in free-living conspecifics sampled in other European localities, despite its prevalence in different sympatric passerines [65-67]. An experimental study showed that certain songbirds, specifically common starlings, are resistant to GRW06 infection [68]. Similar to starlings, innate resistance of tits would explain the absence of GRW06 in these birds. However, given the detected parasite stages in the tits from this study, innate resistance could hardly explain the lack of GRW06 records in Paridae. It has to be noted, that there is a slight chance, that the CISH signals detected in the P. elongatum positive tits from this study could also represent sporozoites, the presence of which does not necessarily imply successful infection and thus susceptibility of the birds. In order to confirm the findings and to prove susceptibility of tits to P. elongatum GRW06, experimental studies are needed.

Aside from tits, the results showed high infection rates in finches, consistent with findings from other studies investigating living birds $[69,70]$. Accordingly, most lineages detected in the finches here were previously recorded in this host family, except for Plasmodium vaughani SYAT05 and Leucocytozoon sp. BT2, found in a goldfinch and a bullfinch, respectively. Plasmodium vaughani SYAT05 typically infects species of Turdidae, most of all blackbirds [1, $3,50]$, however, it has also been recorded in non-Turdidae hosts, including common chaffinches [71, 72]. While infections of finches with SYAT05 seem to be the exception, the parasite stages detected in the blood of the goldfinch suggest complete parasite development in this host species. The same cannot be concluded definitely for the Leucocyotzoon lineage BT2 detected in the bullfinch, as this bird was coinfected with another Leuocytozoon lineage, hampering attribution of the observed parasite stages to either one of the two lineages. However, although BT2 was primarily found in species of Muscicapidae, Phylloscopidae and Sylvidae, it was also recorded in other Fringillidae species [73, 74], providing support for the occurrence in this bird family.

In addition to blood stages, CISH revealed parasite tissue stages in some birds, contributing new data on the exo-erythrocytic development of Haemoproteus and 
Leucocytozoon lineages in passerines. In hawfinches, Leucocytozoon meronts were exclusively found in the kidneys, suggesting this organ to be a common site of exo-erythrocytic development of the detected lineages, consistent with descriptions of renal merogony in other passeriform-specific Leucocytozoon [51, 75-77]. In the hawfinch co-infected with two Leucocytozoon lineages (HAWF7 and COCCO01), multiple meronts were distributed across the renal parenchyma and seemed to develop primarily in epithelial cells of tubules, sometimes leading to expansion of the infected cells, occupying most of the tubular lumen. While meronts found in neighbouring tubular cells equalled in size and maturity, meronts located in distant renal tubules showed varying stages of maturity, suggesting overall asynchronous renal merogony of the parasites. However, as the observed tissue stages in this bird could not be assigned to one of the two detected Leucocytozoon lineages, lineage-dependent developmental differences cannot be excluded.

As the results showed, findings of exo-erythrocytic merogony of Haemoproteus parasites were restricted to single megalomeronts detected in the gizzards of a chaffinch infected with Haemoproteus sp. CCF23 and a bullfinch infected with Haemoproteus sp. EMSPO03. Both lineages were previously recorded in finches $[58,69,70$, 78 ], but have not been morphologically described yet. Megalomeronts have only been documented in nine Haemoproteus species so far, and knowledge about the patterns of Haemoproteus exo-erythrocytic development within different host species remains fragmentary $[51,79]$. In several reports, the formation of megalomeronts were associated with abortive infections in aberrant hosts $[8,10,13,51,60,80]$. However, recent studies demonstrated Haemoproteus megalomeronts in naturally infected passerines, proposing that they are regular stages during exo-erythrocytic development [79, 81]. The findings of the present study support this suggestion, as megalomeronts were found along with erythrocytic stages of the parasites. Notably, the megalomeront found in the bird infected with Haemoproteus sp. EMSPO03 strongly resembled megalomeronts of three closely related lineages of $H$. majoris (PHSIB1, PARUS1, PHYBOR04), sharing the same unique morphological characters such as irregularly formed cytomeres and a thick wall $[79,81]$. Based on the morphological similarities, this study suggest that EMSPO03 also belongs to the $H$. majoris species complex, supporting previous suggestions, that closely related lineages have similarly developing megalomeronts [81]. While EMSPO03 still requires morphological characterization, phylogenetic analyses corroborate its close relationship to other $H$. majoris lineages [79, 82]. Interestingly, in all three other lineages (PHSIB1, PARUS1, PHYBOR04), megalomeronts were particularly numerous in the kidneys of the infected birds, whereas in the finch infected with EMSPO03, only a single megalomeront was found in the gizzard, indicating differences concerning the site of development, which might be a function of the host-lineage combination. Further investigations are needed to elucidate patterns of exo-erythrocytic merogony of $H$. majoris lineages.

\section{Conclusions}

While the findings of this study suggest generally little contribution of haemosporidian infections to morbidity of investigated bird hosts, there are indications that certain Plasmodium lineages at least play a role in overall clinical manifestation, either as main causes or as concurrent disease agents. In order to be able to assess the significance of these infections for particular host species, such as the tits in this study, additional investigations including larger bird sample sizes are inevitable. The present study demonstrates that citizen science can be applied to prospectively collect carcasses of target passerine species, which do find their way into pathological archives less frequently. This approach opened the opportunity to study pathological effects of haemosporidian infections and gain knowledge about exo-erythrocytic development of haemosporidian lineages naturally occurring in passerines.

\section{Supplementary Information}

The online version contains supplementary material available at https://doi. org/10.1186/s12936-021-03949-y.

Additional file 1. Case details for all bird carcasses confirmed positive for haemosporidian parasites by PCR and sequencing.

Additional file 2. Parasite stages of Plasmodium relictum SGS1 and P. elongatum GRW06 detected in a brain section of a coinfected great tit (Parus major) using $\mathrm{CISH}$ and species-specific probes. a Blood stages of $P$. relictum SGS1 in the lumen of a brain vessel, labeled by the $P$. relictum-specific probe (Prel18S). b Parasite stages of P. elongatum GRW06 in another brain vessel of the same infected individual, labeled by the P. elongatum-specific probe (Pelo18S)

\section{Acknowledgements}

We are grateful to all citizen scientists for participating and contributing to this work. Further, we thank Janette Siebert from the Austrian Ornithological Centre $(A O C)$, Vetmeduni Vienna, for providing access to the platform "StadtWildTiere" and website management, and Katharina Loupal from Birdlife Austria for her support with survey publicity. We are also grateful to Gediminas Valkiūnas from the P.B. Šivickis Laboratory of Parasitology, Nature Research Centre Vilnius, for his help concerning parasite morphology. The FWF Austrian Science Fund is acknowledged for financial support.

\section{Authors' contributions}

$\mathrm{TH}, \mathrm{HW}$ and $\mathrm{JH}$ : study conception and design; $\mathrm{TH}, \mathrm{JH}$ : organisation of sampling and communication with citizen scientists; TH, HW: necropsy \& histopathological examination; JH: molecular analyses and probe design; JM: procedure of CISH experiments; $\mathrm{TH}$ : analyses of CISH experiments and drafting of manuscript. All authors read and approved the manuscript. 


\section{Funding}

The study was supported by the Top Citizen Science Funding Initiative (TCS 62) of the FWF Austrian Science Fund.

\section{Availability of data and materials}

The dataset supporting the conclusions of this article is included within the article and its additional files.

\section{Declarations}

\section{Ethics approval and consent to participate}

The study was part of the Top Citizen Science project TCS 62. The citizen science project was conducted following General Data Protection Regulations (EU) $2016 / 679$

\section{Consent for publication}

Not applicable.

\section{Competing interests}

The authors declare that they have no competing interests.

Received: 24 August 2021 Accepted: 8 October 2021

Published online: 23 October 2021

\section{References}

1. Valkiūnas G. Avian malaria parasites and other haemosporidia. 1st Edn. Boca Raton: CRC Press; 2005

2. Valkiūnas G, lezhova TA. Keys to the avian malaria parasites. Malar J. 2018;17:212.

3. Bensch S, Hellgren O, Pérez-Tris J. MalAvi: a public database of malaria parasites and related haemosporidians in avian hosts based on mitochondrial cytochrome b lineages. Mol Ecol Resour. 2009:9:1353-8.

4. Fecchio A, Chagas CRF, Bell JA, Kirchgatter K. Evolutionary ecology, taxonomy, and systematics of avian malaria and related parasites. Acta Trop. 2020:204:105364.

5. Rivero A, Gandon S. Evolutionary ecology of avian malaria: past to present. Trends Parasitol. 2018:34:712-26.

6. Bennett GF, Peirce MA, Ashford RW. Avian Haematozoa: mortality and pathogenicity. J Nat Hist. 1993:27:993-1001.

7. Atkinson CT. Parasitic diseases of wild birds. In: Atkinson CT, Thomas NJ, Hunter DB, editors. Parasit. Dis. wild birds. Oxford: Wiley-Blackwell; 2008.

8. Donovan TA, Schrenzel M, Tucker TA, Pessier AP, Stalis IH. Hepatic hemor rhage, hemocoelom, and sudden death due to Haemoproteus infection in passerine birds: eleven cases. J Vet Diagnostic Investig. 2008;20:304-13.

9. Grilo ML, Vanstreels RET, Wallace R, García-Párraga D, Braga ÉM, Chitty J, et al. Malaria in penguins - current perceptions. Avian Pathol. 2016:45:393-407

10. Ferrell ST, Snowden K, Marlar AB, Garner M, Lung NP. Fatal hemoprotozoal infections in multiple avian species in a zoological park. J Zoo Wildl Med. 2007:38:309-16

11. Vanstreels RET, Kolesnikovas CKM, Sandri S, Silveira P, Belo NO, Ferreira Junior FC, et al. Outbreak of avian malaria associated to multiple species of Plasmodium in magellanic penguins undergoing rehabilitation in southern Brazil. PLoS One. 2014:9:e94994.

12. Vanstreels RET, Braga ÉM, Catão-Dias JL. Blood parasites of penguins: a critical review. Parasitology. 2016;143:931-56.

13. Ortiz-Catedral L, Brunton D, Stidworthy MF, Elsheikha HM, Pennycott T, Schulze $C$, et al. Haemoproteus minutus is highly virulent for Australasian and South American parrots. Parasit Vectors. 2019;12:40.

14. Lapointe DA, Atkinson CT, Samuel MD. Ecology and conservation biology of avian malaria. Ann N Y Acad Sci. 2012;1249:211-26.

15. van Riper C, van Riper SG, Goff ML, Laird M. The epizootiology and ecological significance of malaria in hawaiian land birds. Ecol Monogr 1986;56:327-44.

16. Atkinson $C T$, Dusek RJ, Woods KL, Iko WM. Pathogenicity of avian malaria in experimentally-infected Hawaii Amakihi. J Wildl Dis. 2000;36:197-204.
17. Sijbranda DC Campbell J Gartrell BD, Howe L Avian malaria in introduced, native and endemic New Zealand bird species in a mixed ecosystem. N Z J Ecol. 2016:40:72-9.

18. Schoenle LA, Kernbach M, Haussmann MF, Bonier F, Moore IT. An experimental test of the physiological consequences of avian malaria infection. J Anim Ecol. 2017;86:1483-96

19. Pigeault R, Cozzarolo CS, Choquet R, Strehler M, Jenkins T, Delhaye J, et al Haemosporidian infection and co-infection affect host survival and reproduction in wild populations of great tits. Int J Parasitol. 2018:48:1079-87.

20. Asghar M, Hasselquist D, Hansson B, Zehtindjiev P, Westerdahl H, Bensch $\mathrm{S}$. Hidden costs of infection: chronic malaria accelerates telomere degradation and senescence in wild birds. Science. 2015;347:436-8.

21. Lachish S, Knowles SCL, Alves R, Wood MJ, Sheldon BC. Fitness effects of endemic malaria infections in a wild bird population: the importance of ecological structure. J Anim Ecol. 2011;80:1196-206.

22. Bensch S, Waldenström J, Jonzén N, Westerdahl H, Hansson B, Sejberg $D$, et al. Temporal dynamics and diversity of avian malaria parasites in a single host species. J Anim Ecol. 2007;76:112-22.

23. Atkinson CT, Forrester DJ. Myopathy associated with megaloschizonts of Haemoproteus meleagridis in a wild turkey from Florida. J Wildl Dis. 1987;23:495-8

24. Simpson VR. Leucocytozoon-like infection in parakeets, budgerigars and a common buzzard. Vet Rec. 1991;129:30-2.

25. Raida SR, Jaensch SM. Central nervous disease and blindness in Nankeen kestrels (Falco cenchroides) due to a novel Leucocytozoon-like infection. Avian Pathol. 2000;29:51-6.

26. Beier JC, Strandberg J, Stoskopf MK, Craft C. Mortality in robins (Turdus migratorius) due to avian malaria. J Wildl Dis. 1981;17:247-50.

27. Lederer R, Adlard RD, O'Donoghue PJ. Severe pathology associated with protozoal schizonts in two pied currawongs (Strepera graculina) from Queensland. Vet Rec. 2002:150:520-2.

28. Peirce MA, Lederer R, Adlard RD, O'Donoghue PJ. Pathology associated with endogenous development of haematozoa in birds from southeast Queensland. Avian Pathol. 2004;33:445-50.

29. Howe L, Castro IC, Schoener ER, Hunter S, Barraclough RK, Alley MR. Malaria parasites (Plasmodium spp.) infecting introduced, native and endemic New Zealand birds. Parasitol Res. 2012;110:913-23.

30. Dinhopl N, Nedorost N, Mostegl MM, Weissenbacher-Lang C, Weissenböck H. In situ hybridization and sequence analysis reveal an association of Plasmodium spp. with mortalities in wild passerine birds in Austria. Parasitol Res. 2015;114:1455-62.

31. Rouffaer LO, Steensels M, Verlinden M, Vervaeke M, Boonyarittichaikij R, Martel A, et al. Usutu virus epizootic and Plasmodium coinfection in Eurasian blackbirds (Turdus merula) in Flanders, Belgium. JWildl Dis. 2018;54:859-62.

32. Niedringhaus KD, Fenton HMA, Cleveland CA, Anderson AN, Schwartz D, Alex CE, et al. Case series: virulent hemosporidiosis infections in juvenile great horned owls (Bubo virginianus) from Louisiana and California, USA Vet Parasitol Reg Stud Reports. 2018;12:49-54.

33. Groff TC, Lorenz TJ, Crespo R, lezhova T, Valkiūnas G, Sehgal RNM. Haemoproteosis lethality in a woodpecker, with molecular and morphological characterization of Haemoproteus velans (Haemosporida, Haemoproteidae). Int J Parasitol Parasites Wildl. 2019;10:93-100.

34. Peirce MA, Greenwood AG, Swinnerton K. Pathogenicity of Leucocytozoon marchouxi in the pink pigeon (Columba mayeri) in Mauritius. Vet Rec. 1997;140:155-6.

35. Alley MR, Hunter SA, Webster T. An outbreak of Avian Malaria in Yelloweyed penguins, Megadyptes antipodes. Kokako. 2019;26:21-2.

36. Cannell BL, Krasnec KV, Campbell K, Jones HI, Miller RD, Stephens N. The pathology and pathogenicity of a novel Haemoproteus spp. Infection in wild Little Penguins (Eudyptula minor). Vet Parasitol. 2013;197:74-84.

37. Ilgūnas M, Bukauskaitè D, Palinauskas V, lezhova TA, Dinhopl N, Nedorost $\mathrm{N}$, et al. Mortality and pathology in birds due to Plasmodium (Giovannolaia) homocircumflexum infection, with emphasis on the exoerythrocytic development of avian malaria parasites. Malar J. 2016;15:256.

38. Mukhin A, Palinauskas V, Platonova E, Kobylkov D, Vakoliuk I, Valkiunas G. The strategy to survive primary malaria infection: an experimental study on behavioural changes in parasitized birds. PLoS One. 2016;11:1-15.

39. Fallon SM, Ricklefs RE. Parasitemia in PCR-detected Plasmodium and Haemoproteus infections in birds. J Avian Biol. 2008;39:514-22. 
40. Santos SM, Carvalho F, Mira A. How long do the dead survive on the road? Carcass persistence probability and implications for road-kill monitoring surveys. PLoS One. 2011;6:e25383.

41. Ward MR, Stallknecht DE, Willis J, Conroy MJ, Davidson WR. Wild bird mortality and West Nile virus surveillance: biases associated with detection, reporting, and carcass persistence. J Wildl Dis. 2006;42:92-106.

42. Hars J, Ruette S, Benmergui M, Fouque C, Fournier JY, Legouge A, et al The epidemiology of the highly pathogenic H5N1 avian influenza in mute swan (Cygnus olor) and other Anatidae in the Dombes region (France), 2006. J Wildl Dis. 2008;44:811-23.

43. Eidson M, Komar N, Sorhage F, Nelson R, Talbot T, Mostashari F, et al. Crow deaths as a sentinel surveillance system for West Nile virus in the Northeastern United States, 1999. Emerg Infect Dis. 2001;7:615-20.

44. Chvala S, Bakonyi T, Bukovsky C, Meister T, Brugger K, Rubel F, et al. Monitoring of Usutu virus activity and spread by using dead bird surveillance in Austria, 2003-2005. Vet Microbiol. 2007;122:237-45.

45. Giovannini S, Pewsner M, Hüssy D, Hächler H, Ryser Degiorgis MP, von Hirschheydt J, et al. Epidemic of salmonellosis in passerine birds in Switzerland with spillover to domestic cats. Vet Pathol. 2013;50:597-606.

46. Fukui D, Takahashi K, Kubo M, Une Y, Kato Y, Izumiya H, et al. Mass mortality of eurasian tree sparrows (Passer montanus) from Salmonella typhimurium dt40 in Japan, winter 2008-09. J Wildl Dis. 2014;50:484-95.

47. Dhondt AA, Tessaglia DL, Slothower RL. Epidemic mycoplasmal conjunctivitis in house finches from eastern North America. J Wildl Dis. 1998;34:265-80.

48. Robinson RA, Lawson B, Toms MP, Peck KM, Kirkwood JK, Chantrey J, et al. Emerging infectious disease leads to rapid population declines of common british birds. PLoS One. 2010;5:e12215.

49. Lawson B, Petrovan SO, Cunningham AA. Citizen science and wildlife disease surveillance. Ecohealth. 2015;12:693-702.

50. Himmel T, Harl J, Pfanner S, Nedorost N, Nowotny N, Weissenböck H. Haemosporidioses in wild Eurasian blackbirds (Turdus merula) and song thrushes (T. philomelos): an in situ hybridization study with emphasis on exo-erythrocytic parasite burden. Malar J. 2020;19:1-13.

51. Valkiūnas $G$, lezhova TA. Exo-erythrocytic development of avian malaria and related haemosporidian parasites. Malar J. 2017;16:101.

52. Hellgren $\mathrm{O}$, Waldenström J, Bensch S. A new PCR assay for simultaneous studies of Leucocytozoon, Plasmodium, and Haemoproteus from avian blood. J Parasitol. 2004;90:797-802.

53. Hall TA. BioEdit: a user-friendly biological sequences alignment editor and analysis program for Windows 95/98/NT. Nucleic Acids Symp Ser. 1999:41:95-8

54. Rozas J, Ferrer-Mata A, Sánchez-DelBarrio JC, Guirao-Rico S, Librado P, Ramos-Onsins SE, et al. DnaSP 6: DNA sequence polymorphism analysis of large data sets. Mol Biol Evol. 2017;34:3299-302.

55. Mostegl MM, Richter B, Nedorost N, Maderner A, Dinhopl N, Kulda J, et al. Design and validation of an oligonucleotide probe for the detection of protozoa from the order Trichomonadida using chromogenic in situ hybridization. Vet Parasitol. 2010;171:1-6.

56. Himmel T, Harl J, Kübber-Heiss A, Konicek C, Fernández N, Juan-Sallés C, et al. Molecular probes for the identification of avian Haemoproteus and Leucocytozoon parasites in tissue sections by chromogenic in situ hybridization. Parasit Vectors. 2019;12:282

57. Harl J, Himmel T, Valkiūnas $G$, Weissenböck H. The nuclear 18 S ribosomal DNAs of avian haemosporidian parasites. Malar J. 2019;18:305.

58. Lehikoinen A, Lehikoinen E, Valkama J, Väisänen RA, Isomursu M. Impacts of trichomonosis epidemics on greenfinch Chloris chloris and chaffinch Fringilla coelebs populations in Finland. Ibis. 2013;155:357-66.

59. Ganas P, Jaskulska B, Lawson B, Zadravec M, Hess M, Bilic I. Multi-locus sequence typing confirms the clonality of Trichomonas gallinae isolates circulating in European finches. Parasitology. 2014;141:652-61.

60. Cardona CJ, Ihejirika A, McClellan L. Haemoproteus lophortyx infection in Bobwhite Quail. Avian Dis. 2002;46:249-55.

61. Banda ME, Howe L, Gartrell BD, McInnes K, Hunter S, French NP. A cluster of avian malaria cases in a kiwi management programme. $\mathrm{N}$ Z Vet J. 2013:61:121-6.

62. Vanstreels RET, Dutra DDA, Ferreira-Junior FC, Hurtado R, Egert L, Mayorga LFSP, et al. Epidemiology, hematology, and unusual morphological characteristics of Plasmodium during an avian malaria outbreak in penguins in Brazil. Parasitol Res. 2019;118:3497-508.
63. Dinhopl N, Mostegl MM, Richter B, Nedorost N, Maderner A, Fragner K, et al. Application of in-situ hybridization for the detection and identification of avian malaria parasites in paraffin wax-embedded tissues from captive penguins. Avian Pathol. 2011;40:315-20.

64. Szöllosi E, Cichoń M, Eens M, Hasselquist D, Kempenaers B, Merino S, et al. Determinants of distribution and prevalence of avian malaria in blue tit populations across Europe: separating host and parasite effects. J Evol Biol. 2011;24:2014-24

65. van Rooyen J, Lalubin F, Glaizot O, Christe P. Altitudinal variation in haemosporidian parasite distribution in great tit populations. Parasit Vectors. 2013;6:139.

66. Glaizot O, Fumagalli L, Iritano K, Lalubin F, Van Rooyen J, Christe P. High prevalence and lineage diversity of avian malaria in wild populations of great tits (Parus major) and mosquitoes (Culex pipiens). PLoS One. 2012; 7:e34964.

67. Lynton-Jenkins JG, Bründl AC, Cauchoix M, Lejeune LA, Sallé L, Thiney $A C$, et al. Contrasting the seasonal and elevational prevalence of generalist avian haemosporidia in co-occurring host species. Ecol Evol. 2020;10:6097-111.

68. Ilgūnas M, Palinauskas V, Platonova E, lezhova T, Valkiūnas G. The experimental study on susceptibility of common European songbirds to Plasmodium elongatum (lineage pGRW6), a widespread avian malaria parasite. Malar J. 2019;18:290.

69. Ellis VA, Huang X, Westerdahl $H$, Jönsson J, Hasselquist D, Neto JM, et al. Explaining prevalence, diversity and host specificity in a community of avian haemosporidian parasites. Oikos. 2020;129:1314-29.

70. Mata VA, da Silva LP, Lopes RJ, Drovetski SV. The Strait of Gibraltar poses an effective barrier to host-specialised but not to host-generalised lineages of avian Haemosporidia. Int J Parasitol. 2015;45:711-9.

71. Hellgren $\mathrm{O}$, Križanauskienè A, Hasselquist D, Bensch S. Low haemosporidian diversity and one key-host species in a bird malaria community on a mid-Atlantic island (São Miguel, Azores). J Wildl Dis. 2011;47:849-59.

72. Drovetski SV, Aghayan SA, Mata VA, Lopes RJ, Mode NA, Harvey JA, et al. Does the niche breadth or trade-off hypothesis explain the abundance-occupancy relationship in avian Haemosporidia? Mol Ecol. 2014:23:3322-9.

73. Liu B, Deng Z, Huang W, Dong L, Zhang Y. High prevalence and narrow host range of haemosporidian parasites in Godlewski's bunting (Emberiza godlewskii) in northern China. Parasitol Int. 2019;69:121-5.

74. Synek P, Munclinger P, Albrecht T, Votýpka J. Avian haemosporidians in haematophagous insects in the Czech Republic. Parasitol Res. 2013;112:839-45.

75. Wong STC, Desser SS. Ultrastructural observations on renal schizogony of Leucocytozoon dubreuili in the American robin. J Protozool. 1978;25:302-14.

76. Khan, Fallis AM. Life cycles of Leucocytozoon dubreuili Mathis and Leger, 1911 and L. fringillinarum. Immunol Today. 1991;12:642-58.

77. Gill H, Paperna I. Leucocytozoonosis in the Israeli sparrow, Passer domesticus biblicus Hartert 1904. Parasitol Res. 2005;96:373-7.

78. Palinauskas V, lezhova TA, Križanauskienè A, Markovets MY, Bensch S, Valkiūnas G. Molecular characterization and distribution of Haemoproteus minutus (Haemosporida, Haemoproteidae): a pathogenic avian parasite. Parasitol Int. 2013;62:358-63.

79. Ilgūnas M, Chagas CRF, Bukauskaitè D, Bernotienè R, lezhova T, Valkiūnas $\mathrm{G}$. The life-cycle of the avian haemosporidian parasite Haemoproteus majoris, with emphasis on the exoerythrocytic and sporogonic development. Parasit Vectors. 2019;12:516.

80. Olias P, Wegelin M, Zenker W, Freter S, Gruber AD, Klopfleisch R. Avian malaria deaths in parrots, Europe. Emerg Infect Dis. 2011;17:950-2.

81. Duc M, Ilgūnas M, Valkiūnas G. Patterns of Haemoproteus majoris (Haemosporida, Haemoproteidae) megalomeront development. Acta Trop. 2020:212:105706

82. Nilsson E, Taubert H, Hellgren O, Huang X, Palinauskas V, Markovets MY, et al. Multiple cryptic species of sympatric generalists within the avian blood parasite Haemoproteus majoris. J Evol Biol. 2016;29:1812-26.

\section{Publisher's Note}

Springer Nature remains neutral with regard to jurisdictional claims in published maps and institutional affiliations. 